\title{
Polychromatophilic Erythroblast Count
}

National Cancer Institute

\section{Source}

National Cancer Institute. Polychromatophilic Erythroblast Count. NCI Thesaurus. Code C147418.

The determination of the amount of polychromatophilic erythroblasts present in a sample from an experimental organism. 